\title{
LA IMPORTANCIA DE LA ENSEÑANZA DEL CAMBIO CLIMÁTICO. PROPUESTAS DIDÁCTICAS PARA LA GEOGRAFÍA ESCOLAR ${ }^{1}$
}

\author{
Álvaro-Francisco Morote Seguido \\ Universidad de Valencia \\ alvaro.morote@uv.es \\ ORCID iD: https://orcid.org/0000-0003-2438-4961 \\ Jorge Olcina Cantos \\ Universidad de Valencia \\ jorge.olcina@ua.es \\ ORCID iD: https://orcid.org/0000-0002-4846-8126
}

Recibido: 01/10/2020; Aceptado: 06/08/2021; Publicado: 07/12/2021

Cómo citar este artículo/citation: Morote Seguido, Álvaro-Francisco y Olcina Cantos, Jorge (2021). La importancia de la enseñanza del cambio climático. Propuestas didácticas para la Geografía escolar. Estudios Geográficos, 82 (291), e078. https://doi.org/10.3989/ estgeogr.202189.089

\begin{abstract}
RESUMEN: La enseñanza de la temática del tiempo y clima ha experimentado un notable interés y renovación en los últimos años debido a la preocupación social por las cuestiones ambientales en el marco del proceso de cambio climático actual. Debido a este interés, este trabajo plantea diferentes objetivos. Por un lado, presentar el cambio climático como el proceso ambiental más importante y de efectos más destacados del presente siglo en la superficie terrestre. En segundo lugar, justificar el tratamiento preciso y científico de esta cuestión en el ámbito escolar (Educación Secundaria y Bachillerato) y explicar los principales efectos que ello puede tener en las futuras generaciones. Y tercero, plantear diferentes actividades para la enseñanza del cambio climático en el aula, con sus diferentes aspectos asociados (evolución histórica, efectos en episodios extremos, en elementos climáticos y en la economía y sociedad). La correcta presentación del cambio climático y sus efectos es una cuestión esencial para la formación de las sociedades en el presente siglo tal y como señalan los Objetivos de Desarrollo Sostenible (ODS) de las Naciones Unidas (Agenda 2030) o la propia Ley de Cambio Climático española (mayo de 2021).
\end{abstract}

PALABRAS CLAVE: cambio climático; riesgos atmosféricos; propuestas didácticas; Geografía escolar.

\section{THE IMPORTANCE OF THE CLIMATE CHANGE TEACHING. DIDACTIC PROPOSALS FOR THE SCHOOL GEOGRAPHY}

ABSTRACT: The teaching of weather and climate issues has experienced notable interest and renewal in recent years due to social concern for environmental issues in the context of the current climate change process. Due to this interest, this research raises different objectives. On the one hand, to present climate change as the most important environmental process with the most prominent effects of this century on the earth's surface. Second, justify the precise and scientific treatment of this issue in the school environment (Secondary Education and Baccalaureate) and explain the main effects that this may have on future generations. And third, propose different activities for teaching climate change in the classroom, with its different associated aspects (historical evolution, effects in extreme episodes, in climatic elements and in the economy and society). The correct presentation of climate change and its effects is an essential issue for the formation of societies in this century, as indicated by the Sustainable Development Goals (SDGs) of the United Nations (2030 Agenda) or the Spanish Climate Change Law itself (May 2021).

KEY WORDS: climate change; atmospheric hazards; instruction proposals; school Geography.

1 Esta investigación se inserta en el proyecto "Las representaciones sociales de los contenidos escolares en el desarrollo de las competencias docentes" (PGC2018-094491-B-C32) financiado por el Ministerio de Ciencia, Innovación y Universidades y parte de los resultados que se presentaron en el Taller "Climántica de Respuestas Educativas al Cambio Climático" organizado por el CEFIRE y celebrado entre los días 24-26 de febrero de 2020 en el IES Virgen del Remedio (ciudad de Alicante). 


\section{INTRODUCCIÓN}

La enseñanza de las cuestiones del tiempo y clima ha experimentado un notable interés debido a la preocupación por las temáticas ambientales en el marco de la hipótesis actual de cambio climático (Olcina, 2020). Sin embargo, diferentes autores (MartínezFernández y Olcina, 2019; Morote y Olcina, 2020) han puesto de manifiesto que su conocimiento y enseñanza constituye una tarea compleja e incluso se observa que a la comunidad académica le resulta complicado tener una explicación sencilla de la evolución del clima y su estado actual debido a multitud de factores que intervienen (Ozdem, Dal, Oztuk, Sonmez y Alper, 2014), estereotipos (Morote, Campo y Colomer, 2021a) y noticias falsas transmitidas y, a veces, creadas por los medios de comunicación y redes sociales (Kažys, 2018).

El cambio climático y los extremos atmosféricos, están estrechamente relacionados. Desde la publicación del IV Informe del Intergovernmental Panel on Climate Change (IPCC, 2007) quedó de manifiesto que el comportamiento irregular de la atmósfera terrestre en el contexto del calentamiento climático favorece el desarrollo de fenómenos atmosféricos de rango extremo que ocasionan daños económicos y pérdida de vidas humanas en los territorios afectados. Este proceso, según diferentes autores (Wisner, Blaikie, Cannon y Davis, 2004), debe analizarse dentro de los parámetros del análisis de riesgo, teniendo en cuenta sus tres elementos integrantes: 1) peligrosidad del fenómeno que puede originar un evento potencialmente catastrófico; 2) vulnerabilidad del grupo social o la actividad que puede verse afectada por el desarrollo de un evento natural extremo; y 3) exposición o territorio de afectación de un episodio extremo (Ward et al., 2020). La acción conjunta de estos tres elementos componentes de los procesos de riesgo, en función de los rasgos socio-económicos y la frecuencia de aparición de los eventos extremos y de las características del espacio geográfico que puede ser afectado, determinan el grado de riesgo. De estos tres componentes el factor humano es fundamental en su análisis (White, 1974). En el proceso actual de cambio climático, el proceso físico del calentamiento tendrá efectos diversos en virtud del territorio y sociedad que sea receptora de los efectos atmosféricos de dicho proceso (Arnell, Lowe, Challiner y Osbon, 2019).

En el ámbito internacional, varios trabajos en los últimos años ponen de manifiesto la importancia dedicada a la enseñanza del cambio climático y los riesgos, como en EE.UU. (McWhirter y Shealy, 2018),
Europa (Allea, 2020), o Asia (Ahmad y Numan, 2015). En España, desde la enseñanza de la Geografía y de las Ciencias Sociales no es frecuente encontrar este tipo de trabajos. Existe una dilatada producción científica sobre cómo enseñar Climatología (García de la Vega, 2016; Martínez, 2013; Martínez-Medina y López-Fernández, 2016; Martínez-Ibarra, Arias y Gómez, 2016; Morote y Moltó, 2017; Tonda y Sebastiá, 2003; Valbuena y Valverde, 2006) y, recientemente, sobre el análisis de manuales escolares (MartínezFernández y Olcina, 2019; Morote, 2020). Recientemente se han publicado trabajos sobre la didáctica del cambio climático desde el campo de la Geografía (Morote y Olcina, 2020; 2021) y sobre los riesgos naturales, especialmente los relacionados con episodios de inundación (Cuello, 2018; Morote, 2017; Morote y Pérez-Morales, 2019; Morote y Hernández, 2020; Morote, Hernández y Olcina, 2021b). Además, comienza a haber propuestas editoriales interesantes que explican de forma sencilla, pero con rigor, el proceso actual de cambio climático. Es el caso del trabajo de Nelles y Serrer (2020) que con una secuencia lógica desde los aspectos físicos hasta los humanos explican con un abundante y claro aparato gráfico los diversos elementos que integran un proceso complejo que afecta a la totalidad del medio: clima terrestre, cambios climáticos, criosfera, océanos, eventos extremos, ecosistemas y ser humano.

El cambio climático debe explicarse correctamente desde los niveles educativos básicos para concienciar del papel del ser humano como agente causal y receptor, al mismo tiempo, del actual proceso de calentamiento térmico planetario. Además, la enseñanza sobre este tema y los riesgos asociados es una medida básica para el cumplimiento de los Objetivos de Desarrollo Sostenible (ODS) (Agenda 2030) especialmente el objetivo no13 dedicado a las acciones ante el clima (United Nations, 2015). Asimismo, el factor educación es una de las acciones fundamentales recomendada por el IPCC para la adaptación de las sociedades al cambio climático, ya que una sociedad mejor formada será una sociedad más resiliente ante los efectos extremos vinculados al actual calentamiento planetario (IPCC, 2014). Por ello, el conocimiento del funcionamiento de este fenómeno en las cohortes más jóvenes es fundamental para la propia evolución del proceso de calentamiento planetario, puesto que las acciones de mitigación y adaptación ante este proceso deberán implementarlas las nuevas generaciones a lo largo del presente siglo (Olcina, 2017). Al respecto, cabe manifestar que no se plantea dejar en manos de generaciones futuras la solución al cambio climático 
ya que ésta también está en nuestras manos, pero sí la absoluta necesidad de tener generaciones concienciadas con el tema. De ahí, la urgencia de la formación del profesorado de enseñanza secundaria y Bachillerato en esta cuestión (objeto de estudio) y que sepa transmitir mensajes basados en evidencias científicas (Morote y Olcina, 2020).

En la enseñanza de los riesgos atmosféricos y el cambio climático es importante saber interpretar el territorio y conocer los diferentes factores (humanos y naturales) que interaccionan en él (Fernández, Gómez y Luengo, 2019). Además, el interés en el ámbito educativo sobre esta temática se acrecienta debido a que este constituye uno de los principales desafíos ambientales y sociales del siglo XXI (Chew, 2014; Shepardson y Hirsch, 2020), a pesar de ser un proceso complejo y difícil de entender sin caer en explicaciones banales o catastróficas (Morote y Olcina, 2020). Esto supone un reto para la enseñanza por parte de los/as docentes dada su responsabilidad en formar a la población joven en la comprensión y posible adaptación ante este fenómeno (Eklund, 2018). Pero, cabe poner de manifiesto que estos conceptos, que deben explicarse en las aulas, se conocen como la transposición didáctica, es decir, el paso del saber académico (científico), al saber enseñado, ya que el conocimiento inicial puede sufrir transformaciones para enseñarlo en las aulas (Chevallard, 1991; Lenzen y Smith, 1999). De ahí la importancia de llevar a cabo explicaciones sencillas en función del nivel cognitivo del alumnado, pero correctas, sin caer en errores, estereotipos, influencia de los medios etc., problemas que suelen asociarse a la temática del cambio climático (Kažys, 2018). A estos problemas, además, cabría destacar la formación del profesorado (Morote et al., 2021a) y el escaso rigor científico de los manuales escolares sobre esta temática (Morote y Olcina, 2020).

El interés social que genera este tema ha llegado a la esfera política con la intención de mejorar su implementación en los ámbitos educativos no universitarios. En España, tras la Conferencia de las Naciones Unidas sobre el cambio climático celebrada en 2019 (COP25 Madrid), se produjo el anuncio formal desde el Ministerio de Educación de la inminente inclusión de una asignatura sobre cambio climático en el currículo de las enseñanzas no universitarias. No obstante, como manifestaron en una declaración conjunta el Colegio de Geógrafos de España y la Asociación Española de Geografía (2019), estos contenidos ya se imparten en diferentes asignaturas en los niveles educativos no universitarios. Otra cosa bien distinta es, como indican Morote y Olcina (2020, p. 174) que la información sobre esta temática "sea escasa y quizá, sea necesario prestar una mayor atención y rigor científico a estos contenidos con la apuesta de una mayor y mejor formación del profesorado (actual y futuro) y no tanto la creación de nuevas asignaturas".

Este trabajo parte de una serie de motivaciones para su elaboración: 1 ) el interés que suscita el cambio climático en la sociedad actual y sus efectos debido a la mayor frecuencia de episodios atmosféricos extremos (Iluvias torrenciales, sequías etc.), (IPCC, 2018); 2) los estereotipos y errores conceptuales que suelen asociarse a esta temática, tanto por parte del profesorado actual por su escasa formación e influencia de los medios de comunicación (Morote et al., 2021a), como por el escaso rigor científico de los libros de texto (Morote y Olcina, 2020; 2021); 3) la importancia de estudiar estos contenidos teniendo en cuenta las etapas escolares objeto de estudio como así establece el actual currículo (Real Decreto 1105/2014, de 26 de diciembre, por el que se establece el currículo básico de Educación Secundaria y Bachillerato); 4) la preocupación existente debido a la escasa creatividad que muestran los libros de texto en proponer actividades motivadoras para la explicación de esta temática ya que continúan teniendo una visión informativa y enciclopédica con una escasa visión crítica e interpretativa de los procesos que se dan en el medio (Morote, 2020); y 5) el factor educación como una de las variables no estructurales más importantes para adaptarse al cambio climático.

Se plantean los siguientes objetivos: 1) repasar sucintamente el cambio climático como el proceso ambiental más importante y de efectos más destacados del presente siglo en la superficie terrestre; 2) justificar el tratamiento preciso y científico de esta cuestión en el ámbito escolar (Educación Secundaria y Bachillerato) y explicar los principales efectos que ello puede tener en las futuras generaciones; y 3) plantear diferentes actividades y propuestas didácticas para la enseñanza del cambio climático en el aula, con sus diferentes aspectos asociados (evolución histórica, efectos en episodios extremos, en elementos climáticos, en la economía y sociedad).

\section{FUENTES Y MÉTODOS}

El método de trabajo parte, en primer lugar, de la consulta de diferente documentación. Para desarrollar los objetivos 1 y 2 , ha sido necesario analizar los informes oficiales elaborados por organismos inter- 
nacionales y españoles. A escala internacional destacan los informes del IPCC $(2014 ; 2018)$ que pueden consultarse en su propia web (www.ipcc.ch). También la Agencia Europea de Medio Ambiente dispone de abundante información, accesible en su web sobre el cambio climático y sus efectos en el ámbito europeo (https://www.eea.europa.eu/es/themes/climatechange-adaptation). Asimismo, es interesante la consulta de los trabajos sobre impactos del cambio climático del Joint Research Centre (JRC) de la Comisión Europea (https://ec.europa.eu/knowledge4policy/ organisation/jrc-joint-research-centre_en) y, en particular, la consulta del informe "PESETA" que tiene cuatro ediciones (https://ec.europa.eu/jrc/en/peseta-iv). En el ámbito español, los informes y modelización climática se pueden obtener de la página de la Agencia Estatal de Meteorología (AEMET) que ofrece información detallada al respecto (http://www.aemet.es/es/ serviciosclimaticos/cambio_climat).

Para la propuesta de actividades se ha consultado el actual currículo de Educación Secundaria y Bachillerato. Cabe destacar que en España, el Estado establece las enseñanzas básicas para la Educación Secundaria y Bachillerato en el Real Decreto 1105/2014, de 26 de diciembre. En concreto, los contenidos sobre el cambio climático y riesgos atmosféricos en la asignatura de Geografía se insertan en el $1^{\mathrm{er}}$ ciclo de la ESO ( $1 \%$ y 3 o de ESO) y en 2 o de Bachillerato, donde se pone de manifiesto la importancia de no sólo los factores climáticos (factor peligrosidad) sino también los humanos (factor vulnerabilidad). En cuanto a las propuestas de actividades que se han elaborado en relación con el cambio climático y su incidencia en los principales riesgos atmosféricos que afectan a la región mediterránea (objetivo 3 ) se han tenido en cuenta los contenidos, criterios de evaluación y estándares de aprendizaje. Estas propuestas se han elaborado a modo de "guía" para que la comunidad docente las tome y adapte como propias, tanto a cualquier escala local y/o regional y etapa educativa. Por tanto, se trata de una propuesta general que incluso puede ser adaptada a la Educación Primaria, especialmente para el $3^{\text {er }}$ ciclo (cursos 5ㅇ y 6으).

\section{EVIDENCIAS E INCERTIDUMBRES DEL CAMBIO CLIMÁ- TICO. UNA OPORTUNIDAD PARA LA ENSEÑANZA EN LA GEOGRAFÍA ESCOLAR}

Los datos evidencian sin margen de error los efectos atmosféricos y ambientales del proceso actual de calentamiento causado por efecto invernadero de origen antrópico. Este cambio se manifiesta tanto en los datos de los elementos climáticos como en modificaciones en mecanismos de circulación atmosférica en las diferentes regiones del planeta. En la fachada mediterránea española, el clima actual ya no es el mismo que hace tres décadas. Hay algunos elementos climáticos, como se comentará a continuación, que manifiestan cambios y tendencias diferentes.

A partir de las fuentes consultadas es posible señalar cuatro procesos que ya se registran en las condiciones climáticas del territorio español y que tienen una relación estrecha con el mecanismo planetario de calentamiento global. El primero de ellos es el cambio en las temperaturas. La subida de la temperatura media anual a nivel global es innegable. Para el caso español, este aumento ha sido de 0,8 으 en los últimos cien años, con un ascenso pronunciado desde la década de 1980 (AEMET, 2020). Cabe destacar que la AEMET tiene la base de datos más actualizada para el análisis de la evolución térmica y pluviométrica de España y que gracias a sus informes anuales sobre el estado del clima en España se puede hacer un seguimiento sobre esta cuestión. Existe una amplia producción científica que ha tratado este tema en España desde 1950 en adelante, donde se señala un aumento de la temperatura media, que sigue la tendencia global del planeta. Esta subida es más notable en verano y primavera (Brunet et al., 2007; Del Río, Pinto y Penas, 2011; Del Río, Cano, Herrero y Penas, 2012; González, Penas, Bruneti y Cortesi, 2015; Ríos, Penas y Del Río, 2012); además el análisis de los registros térmicos no muestran unanimidad en si el aumento ha sido mayor para las temperaturas máximas o mínimas. Peña et al. (2021) han analizado la evolución de la temperatura para el periodo $1916-2015$ y han comprobado un aumento generalizado de temperatura, tanto de las máximas como mínimas en las cuatro estaciones. Para el caso de la temperatura máxima, las tasas más altas se han producido en primavera $\left(0,16^{\circ} \mathrm{C} / \mathrm{dec} \pm\right.$ $0,08)$ y verano $\left(0,13^{\circ} \mathrm{C} / \mathrm{dec} \pm 0,06\right)$ y, respecto a las mínimas, las tasas más altas se han registrado en verano $\left(0,13^{\circ} \mathrm{C} / \mathrm{dec} \pm 0,04\right)$ y otoño $\left(0,11^{\circ} \mathrm{C} / \operatorname{dec} \pm 0,05\right)$. Las tasas de tendencia estacional más altas ocurrieron alrededor de la década de 1970, y en las últimas décadas las tasas de ambas variables disminuyeron para todas las estaciones.

No obstante, la manifestación más evidente de la pérdida de confort térmico ha sido el incremento de las denominadas "noches tropicales", en las que el termómetro no desciende de $20^{\circ} \mathrm{C}$ durante las horas nocturnas. Desde 1970 a la actualidad, el número de estos episodios en muchas ciudades españolas se ha 
multiplicado por tres o por cuatro (Olcina, Serrano, Miró y Messeguer, 2019). Este fenómeno es especialmente relevante en el litoral mediterráneo español. Además, desde el año 2000, como ha constatado Núñez (2020), se observa un aumento de noches muy cálidas (las denominadas "noches ecuatoriales", ta $>25 \circ$ C) incluso en algún caso se ha registrado que la temperatura mínima diaria no ha descendido de los 29-30ㄷ, para las que la disciplina climática no encuentra expresión que las caracterice. La ciudad de Valencia, por ejemplo, registra 40 noches al año con temperaturas mínimas por encima de 25으 (20102020) cuando no registraba ninguna noche cálida de estas características en las décadas de 1960 o 1970 (Núñez, 2020).

En segundo lugar, cabe destacar las variaciones estacionales de las precipitaciones y la intensificación de episodios de lluvias de fuerte intensidad horaria. El calentamiento climático actual está alterando la forma de llover que se manifiesta en: 1) cambios en la cuantía, con una tendencia a la disminución de cantidades anuales en todas las regiones españolas, salvo en la fachada cantábrica, donde esta tendencia no se aprecia (Centros de Estudios y Experimentación de Obras Públicas, [CEDEX], 2017). Debe señalarse que en el litoral mediterráneo se registran áreas donde se ha incrementado el volumen de precipitación y otras en las que ha descendido (ver Serrano, Beguería, Saz y De Luis, 2018); 2) cambios en la estacionalidad, proceso que es notable en la mitad este peninsular, donde se observa una disminución de lluvias en primavera y un aumento de lluvias en otoño desde los años ochenta del pasado siglo (De Luis, Brunetti, González, Longares, y Martin-Vide, 2010; González, López, Stepanek, Martin-Vide y De Luis, 2009); 3) cambios en la intensidad de las lluvias, muy significativo en las regiones del mediterráneo español, donde se registran, últimamente, tormentas de alta intensidad horaria, que descargan cantidades entre 50-100 mm., en apenas una hora generando problemas de inundaciones (Monjo y Martín-Vide, 2016; Serrano, 2017); y 4) disminución de las precipitaciones en forma de nieve. En España, en todas las zonas de montaña han disminuido los días de nieve al año (Morán, Herrera, López, Revuelto y Beniston, 2016). Es un proceso general en todo el hemisferio norte en el que España no es una excepción, donde las superficies heladas de montaña han experimentado una reducción muy significativa.

En relación con episodios de inestabilidad y precipitaciones se ha constatado una mayor frecuencia de eventos atmosféricos extremos relacionados con con- figuraciones ondulatorias de la circulación atmosférica en las capas altas de la atmósfera. Desde el comienzo del siglo XXI se está observando que las precipitaciones de origen convectivo, con instalación de "gotas frías" en capas medias-altas de la troposfera, tienen mayor protagonismo sinóptico, frente a las precipitaciones frontales de origen atlántico, lo que indica que se están produciendo cambios en la circulación atmosférica. Son cada vez más numerosos los estudios (Muñoz, Schultz y Vaughan, 2020; Nieto, 2021) que señalan que la pérdida de velocidad de la corriente en chorro polar del hemisferio norte está originando un importante aumento de episodios extremos en latitudes medias. Este hecho estaría ocasionado por el registro de un menor gradiente térmico entre las franjas de latitud como consecuencia del calentamiento global, que se traduciría en una menor velocidad de la corriente en chorro.

Martín-León (2019) ha señalado que diferentes estudios realizados en los últimos años indican que la velocidad media de la corriente en chorro polar se habría reducido un $14 \%$ desde 1980 . Esto supone una circulación ondulatoria más frecuente del chorro con generación de ondas planetarias (crestas y vaguadas) y desplazamientos más rápidos de masas de aire en sentido norte-sur y sur-norte. Por su parte, Muñoz et al. (2020) han confirmado el aumento de la circulación atmosférica de "gotas frías" en latitudes medias planetarias que, en el hemisferio norte, habrían supuesto un incremento del 20\% entre 1960 y 2017. Además, en el sector europeo de las latitudes medias, las zonas donde se habría concentrado la instalación de estas "gotas frías" o Depresiones Aisladas en Niveles Altos (DANAs) de la atmósfera corresponderían al Golfo de Cádiz y al Mediterráneo Occidental en su conjunto.

Tomando como referencia el nivel de los $200 \mathrm{hPa}$, en Europa el número de DANAs al año entre el periodo 1960-1990 se ha mantenido estable, con cerca de 30 episodios anuales. Sin embargo, a partir de 1990 se ha producido un repunte importante, rondando actualmente los 35-40 eventos (un incremento del 16,6$33,3 \%)$. El proceso actual de calentamiento global parece ser una de las causas, ya que se ha demostrado que la corriente en chorro se ha ido desplazando hacia los polos, al igual que la Célula de Hadley y la Zona de Convergencia Intertropical (ZIT); sin olvidar la contracción del vórtice polar y el enfriamiento de la estratosfera. Con un jet más ondulado, se producen bloqueos que favorecen la aparición de ramales subtropicales y polares más débiles, algo muy relacionado con el 
FIGURA 1

SITUACIÓN ATMOSFÉRICA DEL 11 DE SEPTIEMBRE DE 2019

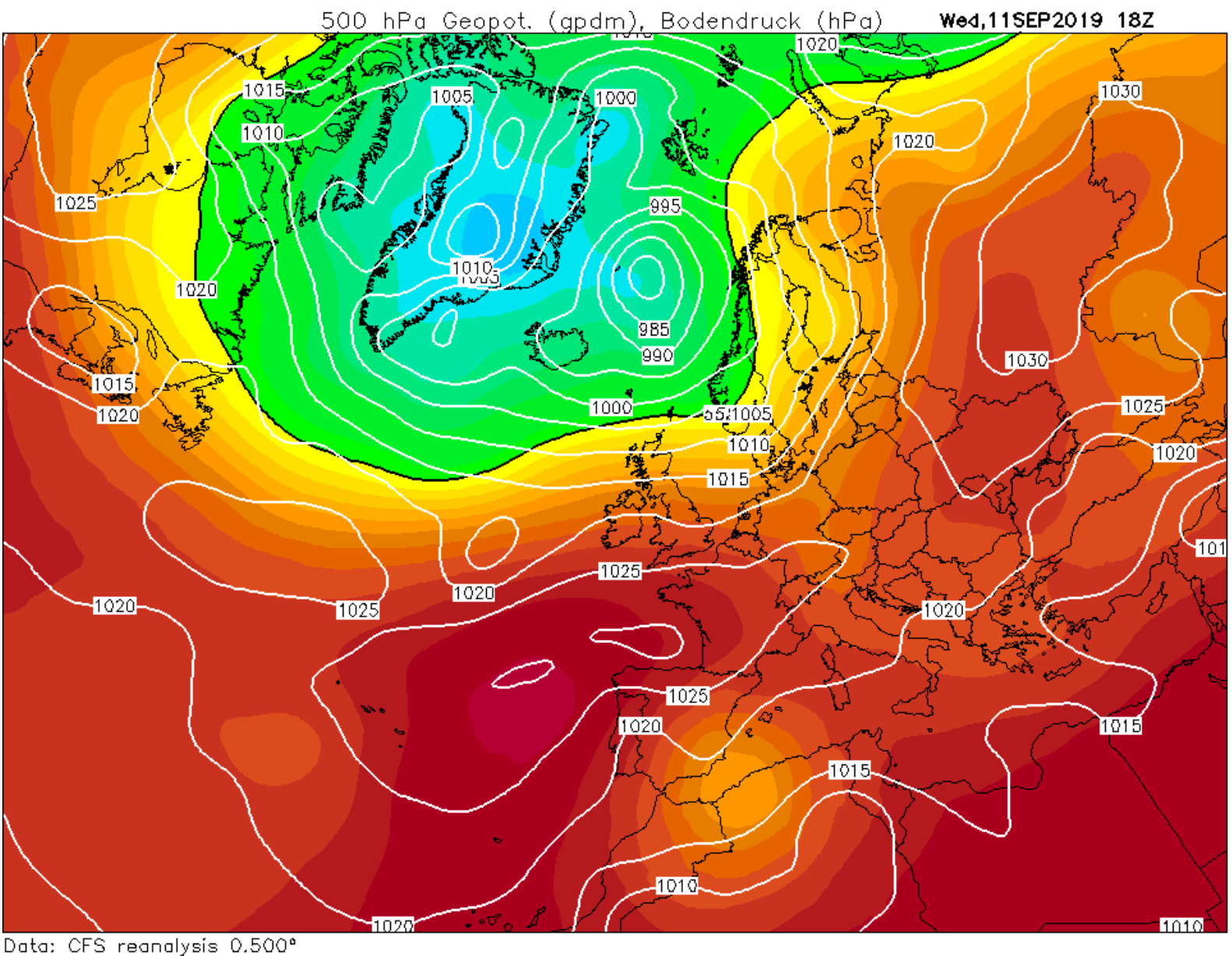

Data: CFS reanalysis 0.500

(c) Wetterzentrale

www.wetterzentrale.de

476480484488492496500504508512516520524528532536540548552556560564568572576580584588592596600

Fuente: Wetterzentrale (2020). https://www.wetterzentrale.de/. Nota: gota fría en el sureste de la península Ibérica (11 de septiembre de 2019). Esta situación dio como resultado una de las inundaciones más graves en la cuenca del río Segura de las últimas décadas tras la de noviembre de 1987.

incremento observado en Europa en el número de gotas frías. Este estudio, al igual que otros (ver Mann et al., 2018; Woolings, 2019), refuerzan la hipótesis de que los eventos extremos de lluvias torrenciales, olas de calor y sequías son cada vez más habituales y extremas como consecuencia de una corriente en chorro más meandrizante (ver Figura 1).

Por lo que respecta al desarrollo de eventos de sequía, diversos estudios señalan la existencia de una tendencia general a la disminución progresiva de las precipitaciones totales anuales en la fachada mediterránea española (CEDEX, 2017) y a la intensificación de los periodos secos (Cramer et al., 2018). No obstante, lo que se observa hasta el momento es que desde inicios del s. XXI están desarrollándose episodios de sequía más cortos e intensos, pero no largas secuencias como las que tenían lugar en la segunda mitad del siglo XX (por ejemplo 1980-84 y 1991-95) (Olcina y Biener, 2019). Esto reforzaría la idea señalada con anterioridad de un mayor dinamismo de la corriente en chorro en las latitudes medias del hemisferio norte, con expansiones más frecuentes de masas frías derivadas del deshielo del Ártico hacia latitudes inferiores, de manera que no se podrían consolidar las situaciones persistentes con dorsal anticiclónica que caracterizan las largas secuencias de sequía en el este peninsular.

Un cuarto cambio manifestado en el contexto del calentamiento climático planetario, en latitudes ibéricas, es el aumento de la temperatura del mar. En las costas españolas ha experimentado un incremento que resulta especialmente significativo en el Medite- 
rráneo occidental. Este ascenso alcanza 1,3ํㅡ anual desde 1980 (Pastor, 2021). El mar Mediterráneo, en estos sectores, está más cálido que hace tres o cuatro décadas, en un proceso de acumulación de calor, especialmente a partir de finales de primavera (mayojunio) y prolongándose en verano hasta bien entrado el otoño (octubre y comienzos de noviembre). Resulta muy destacable que desde el año 2000 se han observado registros de $29-30 \circ \mathrm{C}$ en el centro del verano en las aguas próximas a las Islas Baleares y Argelia. EI período anual en que hay aguas muy cálidas frente a las costas del Mediterráneo español es mucho mayor que hace unas décadas (Figura 2). Esto último tiene una serie de consecuencias que repercuten sobre el clima de esta región climática: un mar más cálido favorece el aumento de las noches tropicales en las poblaciones litorales (Pastor, Valiente y Khodayar, 2020). Esto es debido a que la temperatura del aire no puede descender al encontrarse una masa de agua tan cálida frente a la costa, mientras que por el día las

FIGURA 2

TEMPERATURA DEL AGUA DEL MAR FRENTE A LAS COSTAS DEL LITORAL MEDITERRÁNEO ESPAÑOL (24 DE AGOSTO 2020)

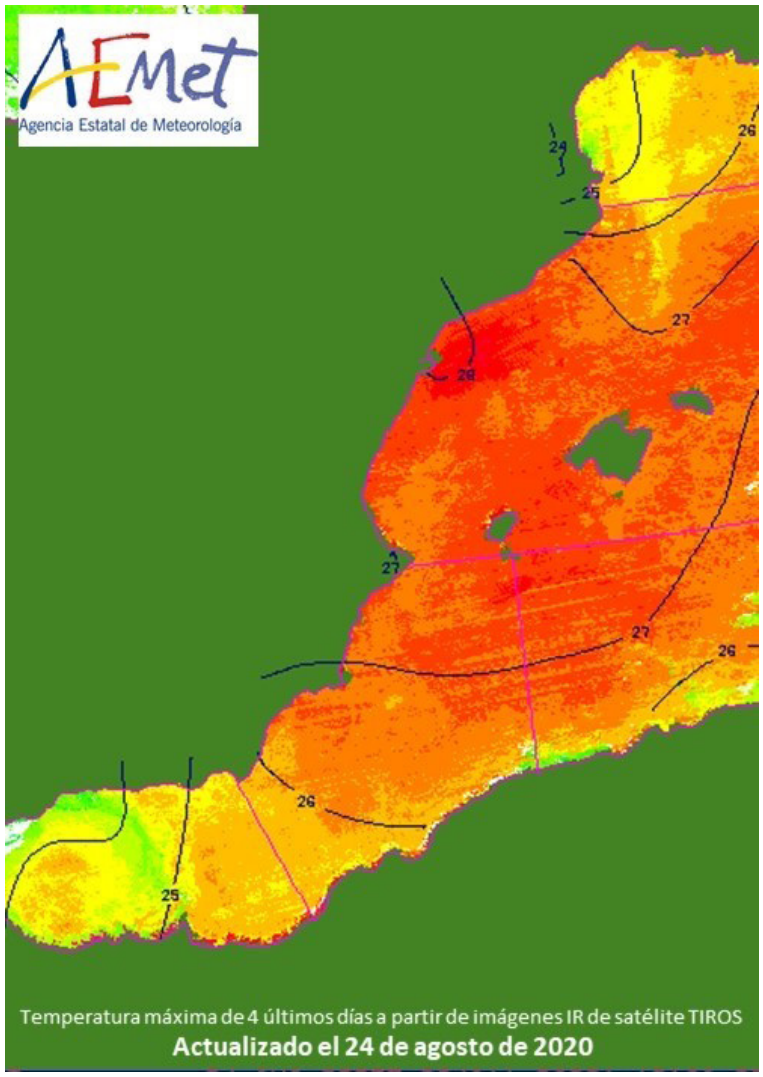

Fuente: AEMET (2020). Nota: la permanencia de aguas muy cálidas es cada vez más prolongada en los meses de verano. brisas pueden contribuir a aumentar la sensación de bochorno, especialmente en aquellos días en los que la temperatura del Mediterráneo alcanza o supera los 28 으 en la fachada litoral, ya que el mar transmite el calor y la humedad al aire situado por encima de él. Y, por otro lado, el calor sensible acumulado en la cuenca marina se transfiere, en forma de calor latente, en los procesos de condensación. Ello implica que esté cambiando la forma de llover en esta parte de España (mayor intensidad horaria y matices comarcales en la cuantía anual) y que el calendario de lluvias intensas no sea exclusivo del otoño sino que se extienda a otras épocas del año (Olcina y Biener, 2019).

\section{PROPUESTA DE ACTIVIDADES SOBRE EL CAMBIO CLIMÁTI- CO EN LA GEOgRAFía ESCOLAR}

La transmisión a la sociedad de las evidencias comprobadas del actual proceso de calentamiento climático es una obligación de la comunicación científica y docente. Este hecho es especialmente notable en la enseñanza no universitaria que forma a la ciudadanía del futuro. Esta comunicación debe cumplir las características básicas de la ética científica: veracidad, rigor, evitar mensajes de finalidad catastrofista no avalados por datos científicos y actualización periódica de los contenidos en función del grado de comprobación de la actual hipótesis de cambio ambiental antropogénico.

Según indica el Real Decreto 1105/2014 de 26 de diciembre, en Educación Secundaria, la asignatura de Geografía e Historia se organiza, en el primer ciclo (de 10 a 3), insertándose los contenidos de Geografía en 10 y $3 \circ$, mientras que en el segundo ciclo (4ㅇ de ESO) se dedica a la Historia. Respecto a los contenidos sobre el cambio climático, cabe indicar que en el primer ciclo no se encuentra ninguna palabra directamente relacionada con este término. No obstante, se entiende que se debe tratar en el Bloque 1 "El medio físico" a la hora explicar Climatología y los problemas ambientales pero, también, en el Bloque 2 "El espacio humano" en relación con los contenidos sobre el desarrollo sostenible y los problemas ambientales (ver Tabla 1). Esto es interesante destacarlo debido a la contemplación de este fenómeno dentro del área más social de la Geografía ya que normalmente el cambio climático se suele insertar en los temarios vinculados con la Geografía Física (Climatología).

En Bachillerato, según el Real Decreto, los contenidos vinculados con el cambio climático se insertan en el Bloque 3 "La diversidad climática y la vegetación" y Bloque 4 "La Hidrografía" de 2o de Bachillerato que, según se indica, aportan: la posibilidad de analizar y 
TABLA 1

CONTENIDOS SOBRE EL CAMBIO CLIMÁTICO QUE SE INSERTAN EN EL CURRÍCULO DE EDUCACIÓN SECUNDARIA Y BACHILLERATO (ASIGNATURA DE GEOGRAFÍA)

\begin{tabular}{|c|c|c|c|}
\hline Curso & Contenidos & Criterios de evaluación & Estándares de aprendizaje \\
\hline $\begin{array}{l}\text { 1er ciclo de ESO (Bloque } 2 \text { "El medio } \\
\text { físico") }\end{array}$ & $\begin{array}{l}\text { - Medio físico: España, Europa y } \\
\text { el mundo: relieve; hidrografía; } \\
\text { clima: elementos y diversidad } \\
\text { paisajes; zonas bioclimáticas; } \\
\text { medio natural: áreas y problemas } \\
\text { medioambientales }\end{array}$ & $\begin{array}{l}\text { - Conocer, describir y valorar la } \\
\text { acción del hombre sobre el medio } \\
\text { ambiente y sus consecuencias. }\end{array}$ & $\begin{array}{l}\text { - Realiza búsquedas en medios } \\
\text { impresos y digitales referidas a } \\
\text { problemas medioambientales } \\
\text { actuales y localiza páginas y recursos } \\
\text { web directamente relacionados con } \\
\text { ellos. }\end{array}$ \\
\hline $\begin{array}{l}\text { 1er ciclo de ESO (Bloque } 2 \text { "El } \\
\text { espacio humano") }\end{array}$ & $\begin{array}{l}\text { - Actividades humanas: áreas } \\
\text { productoras del mundo. } \\
\text { - Aprovechamiento y futuro de } \\
\text { los recursos naturales. Desarrollo } \\
\text { sostenible. }\end{array}$ & $\begin{array}{l}\text { - Conocer y analizar los problemas y } \\
\text { retos medioambientales que afronta } \\
\text { España, su origen y las posibles vías } \\
\text { para afrontar estos problemas. } \\
\text {-Entender la idea de "desarrollo } \\
\text { sostenible" y sus implicaciones. }\end{array}$ & $\begin{array}{l}\text { - Compara paisajes humanizados } \\
\text { españoles según su actividad } \\
\text { económica. } \\
\text { - Define "desarrollo sostenible" } \\
\text { y describe conceptos clave } \\
\text { relacionados con él. }\end{array}$ \\
\hline $\begin{array}{l}\text { 20 Bachillerato (Bloque } 3 \text { “La } \\
\text { diversidad climática y la vegetación") }\end{array}$ & $\begin{array}{l}\text { - Factores geográficos y elementos } \\
\text { del clima. } \\
\text { - Dominios climáticos españoles: su } \\
\text { problemática. }\end{array}$ & $\begin{array}{l}\text { - Obtener y seleccionar información } \\
\text { de contenido geográfico relativo a } \\
\text { la diversidad climática de España } \\
\text { utilizando las fuentes disponibles, } \\
\text { tanto de Internet, como de } \\
\text { medios de comunicación social, o } \\
\text { bibliografía. }\end{array}$ & $\begin{array}{l}\text { - Analiza cómo afecta a España el } \\
\text { cambio climático. } \\
\text { - Utilizando gráficas y estadísticas } \\
\text { que reflejan las lluvias } \\
\text { torrenciales extrae conclusiones } \\
\text { medioambientales. }\end{array}$ \\
\hline $\begin{array}{l}\text { 20 Bachillerato (Bloque } 4 \text { "La } \\
\text { Hidrografía") }\end{array}$ & $\begin{array}{l}\text { - El aprovechamiento de los recursos } \\
\text { hídricos: la incidencia de la sequía y } \\
\text { las Iluvias torrenciales. }\end{array}$ & $\begin{array}{l}\text { - Analizar el aprovechamiento de } \\
\text { los recursos hídricos en nuestro } \\
\text { país incluyendo las características } \\
\text { de sequía y lluvias torrenciales del } \\
\text { clima. }\end{array}$ & $\begin{array}{l}\text { - Sitúa en un mapa de la red } \\
\text { hidrográfica española los grandes } \\
\text { embalses. Deduce consecuencias } \\
\text { analizando también las características } \\
\text { climáticas. } \\
\text { - Analiza y comenta gráficas y } \\
\text { estadísticas que reflejan las épocas } \\
\text { de sequía en relación con un mapa de } \\
\text { tipos de regímenes fluviales de los ríos } \\
\text { de la península. Saca conclusiones }\end{array}$ \\
\hline
\end{tabular}

Fuente: Ministerio de Educación, Cultura y Deporte (2021). Elaboración propia.

realizar interpretaciones globales, sistemáticas e integradas de la realidad territorial; e identificar las unidades territoriales, los paisajes, los resultados de la actividad humana para poder conocer y comprender el espacio. De este modo, la Geografía planteada en este curso tiene como finalidad fundamental dar una interpretación global e interrelacionada de cada fenómeno geográfico y ofrecer los mecanismos que sirvan para dar respuestas y explicaciones a los problemas territoriales de España.

La explicación del cambio climático desde la Geografía resulta especialmente idónea en el conjunto de disciplinas científicas con competencias en enseñanza puesto que esta ciencia aúna aspectos físicos y humanos para la comprensión de fenómenos y procesos complejos (caso del cambio climático). Para la enseñanza de este fenómeno, en algunos aspectos todavía desconocido, resultan fundamentales los mensajes a emitir que deben ser ciertos sin incluir contenidos catastrofistas. La Geografía es la disciplina científica del cambio global, de manera que dispone de competencias especialmente idóneas para la explicación en el aula del cambio climático. En la Tabla 2 se recoge una propuesta de competencias y contenidos sobre este fenómeno a explicar en las etapas formativas del sistema educativo español que podrían complementar a los ya expuestos en el actual currículo.

Los cambios del clima terrestre deben ser explicados en el aula sin caer en extremismos ni catastrofismos. Para la mejor comprensión de este fenómeno deben acomodarse los contenidos a trabajar en el aula, tal y como se muestra en la Tabla 3 . Se deben adaptar los contenidos a cada curso y nivel educativo donde se expliquen cuestiones sobre el tiempo y clima en el aula pero, sin olvidar el factor humano. Así, por ejemplo, en los cursos iniciales de ESO (1으), se puede explicar la relación directa entre emisiones de gases (contaminación) y cambio climático. Esto es, relacionar el proceso actual de cambio climático con el desarrollo humano basado en la quema de combustibles fósiles. Se puede comparar la evolución del clima actual, con otros cambios climáticos ocurridos en épocas históricas (por ejemplo, glaciaciones).

Es importante que el alumnado comprenda que desde mediados del s. XIX el funcionamiento del cli- 
TABLA 2

PROPUESTA CURRICULAR EN LA EDUCACIÓN SECUNDARIA Y BACHILLERATO PARA COMPLEMENTAR LOS CONTENIDOS RELACIONADOS CON EL CAMBIO CLIMÁTICO

\begin{tabular}{|c|c|c|c|}
\hline & Contenidos & Criterios de evaluación & Estándares de aprendizaje \\
\hline $\begin{array}{l}\text { Secundaria (10y } \\
\text { 3어 de ESO) }\end{array}$ & $\begin{array}{l}\text { - Cambios climáticos a lo largo de la } \\
\text { historia terrestre: glaciaciones, pequeña } \\
\text { edad del hielo y calentamiento actual. } \\
\text { - Mapas y gráficos de contaminación } \\
\text { atmosférica y gases de efecto invernadero } \\
\text { (CO2, principalmente). }\end{array}$ & $\begin{array}{l}\text { - Conocer la evolución de las principales } \\
\text { oscilaciones climáticas planetarias en } \\
\text { la Tierra y analizar cómo afectaron al } \\
\text { territorio español. } \\
\text { - Analizar la evolución de los principales } \\
\text { gases de efecto invernadero de causa } \\
\text { antrópica desde la revolución industrial. } \\
\text { - Reconocer las principales } \\
\text { consecuencias derivadas de estos } \\
\text { cambios climáticos que se manifiestan o } \\
\text { se manifestarán en el futuro en España. }\end{array}$ & $\begin{array}{l}\text { - Comprende el cambio climático en el contexto } \\
\text { de la evolución del clima de la Tierra. } \\
\text { - Entiende el cambio climático como un } \\
\text { problema agravado por la contaminación del } \\
\text { ser humano, pero sin perder de perspectiva la } \\
\text { evolución del clima a lo largo de la historia por } \\
\text { causas naturales. } \\
\text { - Interpreta los principales efectos que puede } \\
\text { ocasionar en la sociedad el cambio del } \\
\text { clima debido al aumento de gases de efecto } \\
\text { invernadero por causa antrópica. }\end{array}$ \\
\hline 2 Bachillerato & $\begin{array}{l}\text { - Proceso de cambio climático actual } \\
\text { (relación entre gases de efecto } \\
\text { invernadero de origen antrópico en la } \\
\text { atmósfera y aumento de temperatura). } \\
\text { - Cambio climático y extremos } \\
\text { atmosféricos (relación entre ambos } \\
\text { procesos). } \\
\text { - Mapas sencillos de modelización } \\
\text { climática futura para España o CC.AA. } \\
\text { - Gráficos y estadísticas sobre la evolución } \\
\text { de las precipitaciones (totales anuales y } \\
\text { episodios de lluvias intensas). } \\
\text { - Gráficos y estadísticas sobre el volumen } \\
\text { de agua almacenada en las cuencas } \\
\text { hidrográficas españolas. }\end{array}$ & $\begin{array}{l}\text { - Analizar la relación existente entre } \\
\text { la evolución de los gases de efecto } \\
\text { invernadero de causa antrópica y el } \\
\text { aumento de la temperatura. } \\
\text { - Comprender cuáles son los principales } \\
\text { efectos del cambio climático en España } \\
\text { (riesgos atmosféricos: inundaciones y } \\
\text { sequías). } \\
\text { - Reconocer los principales conflictos } \\
\text { sobre los recursos hídricos y las } \\
\text { regiones españolas más afectadas, } \\
\text { tanto por cuestiones climáticas como } \\
\text { por factores humanos (actividades que } \\
\text { demandan una gran cantidad de agua). } \\
\text { - Proponer medidas de adaptación al } \\
\text { cambio climático. }\end{array}$ & $\begin{array}{l}\text {-Entiende el cambio climático como proceso } \\
\text { de efectos socio-económicos en su territorio } \\
\text { (España o CCAA). } \\
\text { - Interpreta los principales riesgos atmosféricos } \\
\text { asociados que se están incrementado debido al } \\
\text { cambio climático (inundaciones y sequías). } \\
\text { - Entiende estos riegos como resultado de la } \\
\text { interacción del factor peligrosidad (efectos del } \\
\text { cambio climático), vulnerabilidad y exposición } \\
\text { (actividades y comportamientos de la sociedad, } \\
\text { percepción del riesgo, etc.). } \\
\text { - Analiza los principales conflictos sobre el agua } \\
\text { en España (causas y consecuencias) y propuesta } \\
\text { de soluciones. } \\
\text { - Propone medidas de adaptación al cambio } \\
\text { climático. }\end{array}$ \\
\hline
\end{tabular}

Fuente: elaboración propia.

ma terrestre ya no es exclusivamente natural, sino que está influido por la mano del ser humano (emisiones, contaminación atmosférica). En cursos superiores ( 30 de ESO) se puede profundizar en los efectos en los elementos climáticos (temperaturas, precipitaciones, fusión de hielos, subida del nivel del mar, etc.), de manera que, al final de la etapa formativa de la ESO el alumnado pueda tener una idea de lo que es el cambio climático. De esta forma, la transición al Bachillerato y la enseñanza de estos contenidos en la asignatura de Geografía en 20 (optativa), puede ser interesante para que los discentes: 1) comprendan las repercusiones socio-económicas del cambio climático actual y su relación con la mayor frecuencia prevista de desarrollo de episodios extremos (inundaciones, sequías, temporales, etc.); 2) analicen cómo el ser humano está agravando estos riesgos; y 3) propongan medidas de adaptación.

La enseñanza del cambio climático en las aulas de Educación Secundaria y Bachillerato debe asumirse, por tanto, como un contenido básico en la formación del alumnado y debe aunar rigor y amenidad. La sociedad se enfrenta a procesos atmosféricos complejos, de fundamentación físico-química difícil, incluso en los niveles educativos universitarios que deben ex-
TABLA 3

PROPUESTA DE INCORPORACIÓN DEL CAMBIO CLIMÁTICO EN LA ENSEÑANZA DEL TIEMPO Y CLIMA EN LOS NIVELES EDUCATIVOS DE ESO Y BACHILLERATO

\begin{tabular}{|c|c|c|}
\hline 19 ESO & 3 ESO & 2 Bachillerato \\
\hline $\begin{array}{l}\text { Idea principal: } \\
\text { - Causa que origina } \\
\text { el proceso actual } \\
\text { de calentamiento } \\
\text { planetario. } \\
\text { - El cambio climático } \\
\text { actual tiene como } \\
\text { causa principal } \\
\text { la emisión de } \\
\text { gases de efecto } \\
\text { invernadero. Es un } \\
\text { problema ambiental } \\
\text { (contaminación de } \\
\text { la atmósfera) con } \\
\text { repercusiones en los } \\
\text { procesos climáticos. }\end{array}$ & $\begin{array}{l}\text { Idea principal: } \\
\text { - Efectos en elementos } \\
\text { atmosféricos y } \\
\text { ambientales. } \\
\text { - El calentamiento } \\
\text { climático tiene efectos } \\
\text { en los elementos } \\
\text { climáticos principales } \\
\text { (temperaturas, hielos, } \\
\text { precipitaciones) y en } \\
\text { la subida del nivel del } \\
\text { mar (tema climático). }\end{array}$ & $\begin{array}{l}\text { Idea principal: } \\
\text { - Efectos en } \\
\text { la sociedad y } \\
\text { las actividades } \\
\text { económicas. } \\
\text { - El cambio climático } \\
\text { en España: problema } \\
\text { para el futuro de } \\
\text { la economía y el } \\
\text { territorio (mayor } \\
\text { frecuencia eventos } \\
\text { extremos). }\end{array}$ \\
\hline & 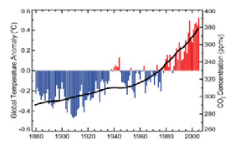 & \\
\hline
\end{tabular}

Fuente: elaboración propia. 
TABLA 4

PROPUESTA DE ACTIVIDADES PRÁCTICAS PARA EL APRENDIZAJE DEL CAMBIO CLIMÁTICO EN LOS NIVELES DE EDUCACIÓN SECUNDARIA Y BACHILLERATO

\begin{tabular}{|c|c|c|}
\hline $\begin{array}{c}10 \text { ESO } \\
\text { Actividades en el aula }\end{array}$ & $\begin{array}{c}3 \circ \text { ESO } \\
\text { Actividades en el aula }\end{array}$ & $\begin{array}{c}2 \circ \text { Bachillerato } \\
\text { Actividades en el aula }\end{array}$ \\
\hline $\begin{array}{l}\text { 1. Medición de temperatura ambiental con } \\
\text { termómetro en diferentes áreas del centro } \\
\text { educativo (clase, patio) o de los alrededores (calle, } \\
\text { manzana, parque). } \\
\text { Objetivo: } \\
\text { - Comprobar los cambios que experimenta la } \\
\text { temperatura en diferentes ambientes. Que el } \\
\text { alumno pueda percibir la sensación de esos } \\
\text { cambios. }\end{array}$ & $\begin{array}{l}\text { 1. Entrevista con familiares mayores para que } \\
\text { comenten su sensación sobre el cambio del clima } \\
\text { o sobre eventos atmosféricos extremos vividos en } \\
\text { épocas pasadas. } \\
\text { Objetivo: } \\
\text { - Comprobar las alteraciones que haya podido } \\
\text { experimentar el clima y sus manifestaciones } \\
\text { atmosféricas en épocas pasadas en comparación } \\
\text { con el presente a partir de la percepción de la } \\
\text { población. }\end{array}$ & $\begin{array}{l}\text { 1. Visualización de documental sobre efectos de } \\
\text { inundaciones y/o sequías en algún territorio que } \\
\text { haya padecido este episodio recientemente. } \\
\text { Objetivo: } \\
\text { - Comprobar los efectos de destrucción y pérdidas } \\
\text { económicas y humanas que originan estos } \\
\text { eventos extremos. }\end{array}$ \\
\hline $\begin{array}{l}\text { 2. Análisis del aumento del parque de vehículos } \\
\text { en el país, región y ciudad donde se vive. } \\
\text { Objetivo: } \\
\text { - Comprobar que una de las causas importantes } \\
\text { de emisiones de gases de efecto invernadero a la } \\
\text { atmósfera es por causa humana (contaminación). }\end{array}$ & $\begin{array}{l}\text { 2. Comparación de series oficiales de temperatura } \\
\text { de tu ciudad, región o país (1960-90 y 1980-2010). } \\
\text { Elaboración de gráficas. } \\
\text { Objetivo: } \\
\text { - Comprobar el aumento de temperatura } \\
\text { registrado en las últimas décadas por efecto del } \\
\text { calentamiento climático. }\end{array}$ & $\begin{array}{l}\text { 2. Demostración en el aula de modelos de } \\
\text { evolución de las temperaturas en el continente } \\
\text { europeo y el área mediterránea. } \\
\text { Objetivo: } \\
\text { - Comprobar la importancia del problema en el } \\
\text { territorio ibérico y cuenca del Mediterráneo. Debate } \\
\text { en el aula sobre sus efectos sociales y económicos. }\end{array}$ \\
\hline $\begin{array}{l}\text { 3. Análisis de cómo ha cambiado la fisonomía de } \\
\text { la ciudad en los últimos } 50 \text { años (comparación de } \\
\text { fotografía aérea, por ejemplo, entre 1970-2020). } \\
\text { Objetivo: } \\
\text { - Comprobar si ha mejorado o empeorado el } \\
\text { confort urbano (zonas verdes, zonas de agua) y } \\
\text { sus efectos en las temperaturas. }\end{array}$ & $\begin{array}{l}\text { 3. Comparación de imágenes o fotografías de } \\
\text { pérdida de hielo en alguna montaña de tu país o } \\
\text { región. O imagen de satélite con pérdida de masa } \\
\text { de hielo del Polo Norte. Apoyo de esta actividad } \\
\text { con el análisis de noticias sobre este fenómeno. } \\
\text { Objetivo: } \\
\text { - Valorar el impacto de la subida de temperatura } \\
\text { sobre las masas de hielo. }\end{array}$ & $\begin{array}{l}\text { 3. Análisis de cómo puede influir el riesgo de } \\
\text { inundación y de sequía en tu ciudad. } \\
\text { Objetivo: } \\
\text { - Valorar la vulnerabilidad del entorno local del } \\
\text { alumnado atendiendo al riesgo de inundación, } \\
\text { con el apoyo de diferentes fotografías áreas } \\
\text { para comprobar la evolución de su ciudad } \\
\text { (ocupación de zonas inundables, incremento } \\
\text { de la impermeabilidad, construcción de } \\
\text { infraestructuras, etc.). } \\
\text { - Con estas imágenes también se valorará la } \\
\text { vulnerabilidad del territorio frente a la sequía. } \\
\text { Para ello se analizará el tipo de construcción de } \\
\text { vivienda (urbanizaciones de baja densidad con } \\
\text { jardín y/o piscina, otros usos urbanos, etc.), y } \\
\text { datos sobre oferta de agua. }\end{array}$ \\
\hline
\end{tabular}

Fuente: elaboración propia.

plicarse atendiendo a unos objetivos de aprendizaje claros para cada etapa (Tabla 3). Por ello, es interesante plantear actividades prácticas que se pueden realizar de forma individual o grupal, con sesiones de puesta en común en el aula. La Tabla 4 presenta una relación de actividades que pueden desarrollarse en los diferentes niveles en los que la explicación del cambio climático es necesaria dentro de los contenidos de la asignatura de Geografía. Sin olvidar que se pueden esbozar proyectos educativos en cada curso en colaboración con materias de Ciencias Naturales, Historia, Economía, Arte, etc. (trabajo por ámbitos).

En 30 de ESO y 2 o de Bachillerato puede ser interesante plantear actividades que permitan la comparación del clima actual con los climas del pasado a escala regional para comprender la entidad del proceso de calentamiento planetario. Un mapa con ubicación de pozos de nieve en el territorio próximo y la explicación de su funcionamiento en el pasado permite hacerse una idea del cambio significativo en la tendencia de temperaturas experimentado en el clima de la Tierra en las tres últimas centurias (Figura 3). Asimismo, sería necesaria la consulta de mapas con la extensión del hielo en épocas glaciares (Cuaternario) para mostrar que el clima terrestre siempre ha cambiado. Esta idea es muy oportuna para situar el proceso actual de calentamiento global, dentro de un contexto más amplio de cambios climáticos ocurridos a lo largo de la historia de la Tierra. Y además, como se ha señalado, la enseñanza del cambio climático puede realizarse, bien en las asignaturas de Geografía en los niveles de Educación Secundaria y Bachillerato o bien como proyectos por ámbitos que integre diferentes materias que compartan contenidos sobre este fenómeno (ver Tabla 5). Asimismo, en relación a la plasmación práctica de esta actividad sería necesario (y no siempre resulta sencillo), diferenciar frente al alumnado las distintas escalas temporales de los fenómenos que se están analizando. 

CAMBIOS CLIMÁTICOS OCURRIDOS A LO LARGO DE LA HISTORIA DE LA TIERRA

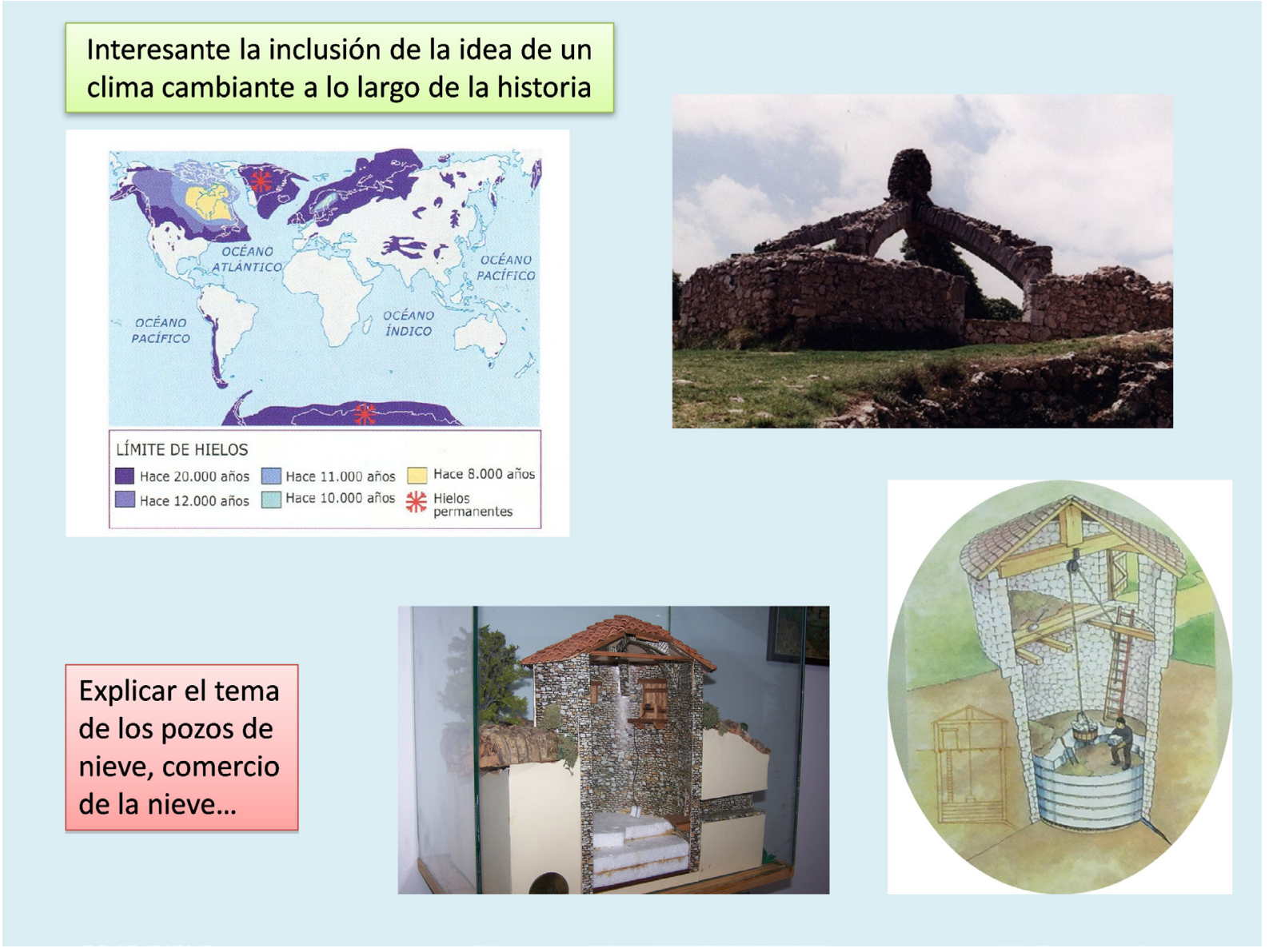

Fuente: Elaboración propia. Nota: para entender el cambio climático actual es interesante proponer una actividad de estudio del clima del pasado. Los pozos de nieve pueden dar claves del importante cambio en la tendencia de temperaturas en una región, desde el siglo XVI a la actualidad.

\section{Discusıón}

en este trabajo se ha analizado la importancia de la enseñanza del cambio climático en los niveles educativos no universitarios como el proceso ambiental más importante y de efectos más destacados del presente siglo en la superficie terrestre. Se ha justificado su tratamiento preciso y científico de esta cuestión en el ámbito escolar. Con esta justificación resulta necesaria no sólo la propuesta de actividades en vinculación con los efectos de este fenómeno como son los principales riesgos atmosféricos asociados en la región mediterránea, sino también las relacionadas con las medidas de adaptación. Lo que se ha pretendido en este trabajo ha sido proponer diferentes actividades en la Educación Secundaria y Bachillerato que puedan servir como guía para la comunidad docente y que puedan ser adaptadas a la escala local y/o regional teniendo en cuenta los efectos del cambio climático en España.

Estas propuestas pretenden mejorar la enseñanza de esta temática en el ámbito escolar, y ello debido a varias cuestiones que aún persisten en las aulas de Geografía y que impiden una transmisión en las aulas con el suficiente rigor científico: 1 ) en las clases de Geografía el libro de texto sigue siendo el principal recurso utilizado y además, estos destacan por su escaso rigor científico y notablemente influido por los medios de comunicación y excesivo catastrofismo de la información (Morote y Olcina, 2020); 2) notable influencia de los medios de comunicación en la concepción del profesorado de la información sobre el cambio climático; y 3) la escasa formación del profesorado sobre esta temática (Morote et al., 2021a). 
TABLA 5

ENSEÑANZA DEL CAMBIO CLIMÁTICO POR PROYECTOS. MATERIAS QUE COMPARTEN LA TEMÁTICA EN EDUCACIÓN SECUNDARIA Y BACHILLERATO

\begin{tabular}{|c|c|}
\hline Materia & Temática compartida \\
\hline Arte & $\begin{array}{l}\text { - Representaciones pictóricas de elementos climáticos. } \\
\text { - Estudio de autores característicos (Velázquez, Goya, } \\
\text { Tiziano, Constable, etc.), que han representado en sus } \\
\text { obras elementos del clima. }\end{array}$ \\
\hline Biología & $\begin{array}{l}\text { - Adaptación de especies a cambios climáticos a lo largo de } \\
\text { la historia de la Tierra. } \\
\text { - Alteración actual de especies de flora y fauna. }\end{array}$ \\
\hline Economía & $\begin{array}{l}\text { - Efectos en las actividades económicas. } \\
\text { - Necesidad de cambiar el modelo energético que } \\
\text { alimenta el actual modelo económico en las sociedades } \\
\text { occidentales. }\end{array}$ \\
\hline Geografía & $\begin{array}{l}\text { - Distribución de los climas terrestres y relación con la } \\
\text { ocupación humana existente. } \\
\text { - Alteraciones actuales en los elementos climáticos } \\
\text { (temperaturas y precipitaciones). }\end{array}$ \\
\hline Geología & $\begin{array}{l}\text { - Épocas glaciares. } \\
\text { - Grandes erupciones volcánicas y efectos en el clima } \\
\text { terrestre. } \\
\text { - Alteraciones actuales en formas de relieve por } \\
\text { ocupación humana. Problemas derivados (inundaciones, } \\
\text { deslizamientos). }\end{array}$ \\
\hline Historia & $\begin{array}{l}\text { - Cambios climáticos y eventos atmosféricos extremos y } \\
\text { sus efectos en acontecimientos históricos importantes } \\
\text { de la historia universal (Prehistoria, crecidas del Nilo en } \\
\text { Egipto, Batalla de Empel, Revolución Francesa, batallas de } \\
\text { la Segunda Guerra Mundial), etc. }\end{array}$ \\
\hline Literatura & $\begin{array}{l}\text { - Relatos de aspectos atmosféricos o climáticos en novelas } \\
\text { clásicas. }\end{array}$ \\
\hline
\end{tabular}

Fuente: elaboración propia.

Morote y Olcina (2020) han destacado los errores y aciertos tras analizar los principales libros de texto que se utilizan en el $3^{\text {er }}$ ciclo de Educación Primaria y que como explica Serantes (2015), se reproducen en Secundaria. Morote y Olcina (2020), por ejemplo, han analizado que no hay unanimidad de criterios para explicar las causas y consecuencias del cambio climático, incluso entre las mismas editoriales. En los libros de texto se destaca la importancia del $\mathrm{CO}_{2}$ como principal gas de efecto invernadero, pero no se indica que el principal gas de efecto invernadero presente en la atmósfera es el vapor de agua. Abbot et al. (2019) han destacado, al respecto, que el $85 \%$ de los libros de texto no mostraban la interacción humana con los procesos del ciclo del agua.

En relación a las causas de los extremos hídricos (inundaciones y sequías) el análisis de los libros de texto demuestra que en la inmensa mayoría se concluye que la causa principal de las inundaciones y las sequías es el cambio climático, mientras que la presencia del factor humano (vulnerabilidad entendida como acción imprudente del ser humano sobre el territorio) es prácticamente nula (Morote y Olcina, 2020). Sin embargo, según indican diferentes informes internacionales, estos riesgos no son un efecto directo del proceso del calentamiento en la actualidad, sino que se estima que serán más frecuentes e intensos en el futuro (IPCC, 2018). Esto es clave, como ya han dejado constancia diferentes informes sobre los efectos de este fenómeno, ya que existe la necesidad de tratar este factor (vulnerabilidad) para tratar de hacer frente y adaptarse al cambio climático (European Environment Agency [EEA], 2017). Estas ideas (percepción de que el cambio climático es la causa principal), incluso está repercutiendo en la percepción del futuro profesorado. Por ejemplo, en un reciente estudio en el ámbito mediterráneo (profesores en formación de Educación Secundaria de la especialidad de Geografía e Historia de las universidades de Valencia y Murcia), se ha constatado como la principal causa de este fenómeno es la acción del ser humano (contaminación; el $64,8 \%$ en la UV y el $73,8 \%$ en la UM) y los efectos que se perciben son, principalmente, el aumento de la temperatura, fenómenos meteorológicos extremos, cambio de las estaciones, cambios bruscos del tiempo, etc. (Morote y Moreno, 2021).

Por lo que respecta al uso de noticias de prensa en el aula, es necesaria la visión del profesorado a la hora de valorar la veracidad de la información que tratan y su empleo como recurso docente (Martín-Vide, 2009). En el ámbito internacional, Kažys (2018) también explica el problema que supone este hecho (falsedad y manipulación), mientras que Allen, McAleer y McHardy-Reid (2018) destacan la influencia sobre las Ilamadas noticias "falsas" (fake news) sobre la percepción de la sociedad. Poortinga, Whitmarsh, Steg, Böhm y Fisher (2019) señalan la importancia de conocer la percepción social del cambio climático a la hora de diseñar políticas de educación ambiental que mejoren el conocimiento de este proceso. Estos autores indican que cabría preguntarse si esta misma influencia está contribuyendo en la percepción del profesorado (estereotipos) y la información que se recoge en los libros de texto. Para el primer caso, Morote et al. (2021a), sobre el profesorado en formación en Educación Primaria, estos autores han comprobado que el $86,2 \%$ recibe la información sobre el cambio climático desde los medios audiovisuales e internet, mientras que tan sólo el 5,3\% afirma recibir esta información desde la universidad. También, esta influencia de los estereotipos sobre este fenómeno queda reflejada en la información insertada en los libros de texto. Por ejemplo, García, Pardo y Rebollo (2009) han analizado como en estos recursos predominan las referencias 
externas a los manuales escolares vinculadas mayoritariamente con direcciones web, a veces manejadas como fuente de procedencia de la información, pero principalmente como medio para ampliar conocimientos o desarrollar determinadas actividades. Morote y Olcina (2020) ponen de manifiesto que los efectos principales del cambio climático que se reflejan en estos recursos son los fenómenos climáticos extremos (inundaciones y sequías) y la incorporación de imágenes de desastres naturales que poco o nada tienen que ver con un "cambio del clima" como es la inclusión de imágenes de inundaciones causadas por el Monzón de verano en el sur de Asia o de fotografías sobre paisajes semiáridos de Almería como ejemplo de "desierto" para explicar la sequía.

La formación del profesorado en estas materias, aspecto clave del proceso educativo, merece mayor atención por la administración o los propios centros educativos. La carencia de acciones formativas en este sentido lleva consigo una excesiva dependencia de los libros de texto que, como ya se ha comentado, tienden a reproducir con muy poco rigor científico este fenómeno y además, notablemente influenciados por los medios de comunicación. Un estudio llevado a cabo sobre los riesgos de inundación (Morote y Hernández, 2020) ha constatado que sólo el $21,3 \%$ del futuro profesorado en Educación Primaria había recibido formación sobre esta temática, destacando que esta procedía de los libros de texto, protocolos de emergencia que se hacían en las escuelas (charlas o simulacros) y, en menor medida, explicaciones sobre episodios pasados o sobre la gota fría. Por tanto, esta escasa formación puede inducir a que lo traten con poco rigor o incluso que no lo traten. A ello, además, cabría sumar que la mayoría del profesorado de Educación Secundaria y Bachillerato que imparte la asignatura de Geografía no tiene una formación disciplinar en contenidos geográficos, ya que suelen ser del ámbito de la Historia, Historia del Arte, Economía, etc. (Parra y Morote, 2020).

La enseñanza del cambio climático desde una orientación didáctica basada en problemas sociales y ambientalmente relevantes es una necesidad para lograr una sociedad y ciudadanía críticas, ayudándoles a interpretar las cuestiones ambientales y territoriales de su tiempo (Martínez-Fernández y Olcina, 2020). Es necesario fomentar un espíritu crítico sobre la interpretación de la información para, de esta manera, adquirir un conocimiento más real y significativo sobre el cambio climático actual. Esto mismo ya ha sido puesto de manifiesto por Arrebola y Martínez (2017) para el caso de la tipología de actividades que se insertan en libros de texto (Educación Primaria). Se debe fomentar la explicación de las principales cuestiones de este fenómeno apoyándose con información y datos proporcionados por diferentes trabajos científicos y contrastar, por ejemplo, con las noticias diarias que aparecen en los medios de comunicación o incluso la información facilitada en los libros de texto. Este hecho ha sido señalado por Serantes (2015) en su propuesta de incorporación de actividades para la resolución de problemas relacionados con el cambio climático y actividades y contenidos de carácter local en los libros de texto de Educación Secundaria. En esta línea es interesante destacar las experiencias que se están desarrollando en países como Reino Unido a través de la Geographical Association en Educación Primaria desde hace varias décadas con el análisis de estudios de caso en los que se exponen trabajos sobre el cambio climático (Greenwood, 2018). En este país se han incorporado profesores especialistas sobre el cambio climático en los centros de Educación Primaria y Secundaria. Y ello debido a que se trata de una de las prioridades educativas, convirtiéndose en el primer país del mundo en contar con profesorado acreditado por las Naciones Unidas para impartir docencia sobre este fenómeno (Ecoinventos, 2019).

Comienza a haber propuestas editoriales interesantes que explican de forma sencilla, pero con rigor, el proceso actual de cambio climático. Es el caso del trabajo de Nelles y Serrer (2020) que con una secuencia lógica desde los aspectos físicos hasta los humanos explican, con un abundante y claro aparato gráfico, los diversos elementos que integran un proceso complejo que afecta a la totalidad del territorio: clima terrestre, cambios climáticos, criosfera, océanos, eventos extremos, ecosistemas y ser humano. En esta línea, Scharmacher-Schreiber y Stephanie (2020) apuestan por un método de pregunta-respuesta en su trabajo sobre el cambio climático orientado a los niveles básicos de la enseñanza, aunque válido también para el gran público: ¿se está volviendo el clima cada vez más cálido? ¿Se puede sentir una diferencia de un grado?). Con el mismo método de pregunta-respuesta Masters (2020) plantea más de un centenar de curiosidades para conocer el clima y el cambio climático, incorporando un aparato gráfico interesante de gran utilidad para su uso en los niveles educativos básicos.

\section{CONCLUSIONES}

El presente trabajo ha pretendido proponer la mejora de la enseñanza del cambio climático en la Geografía escolar, a partir de actividades que puedan ser- 
vir de guía para la comunidad docente. No obstante, es necesario reconocer las limitaciones del mismo debido a los numerosos problemas y desafíos con los que se enfrentan día a día el profesorado: extenso temario; presión por acabarlo en tiempo y forma (a veces muy cortos), especialmente en 20 de Bachillerato para preparar la Evaluación de Acceso a la Universidad (EvAU); alumnado poco motivado y obligado a asistir a clase (hasta los 16 años); un temario de Geografía aun excesivamente enciclopédico y con escasa presencia de actividades y contenidos problemáticos que puedan permitir que los/as alumnos/as vean esta ciencia de utilidad; un profesorado que en numerosos casos no tiene formación disciplinar en Geografía y que se ve obligado a dar estos contenidos, etc.

De ahí, que el trabajo tenga una orientación de guía útil capaz de adaptarse a cualquier territorio de nuestro país. Para la formación del profesorado de Educación Secundaria y Bachillerato en esta temática es necesario incorporar contenidos sobre cambio climático en el Máster de Formación del Profesorado en Educación Secundaria. Y ello debido a que la mayoría del alumnado de este postgrado procede de los grados de Historia e Historia del Arte. Por ello, la formación disciplinar, en este caso, sobre el cambio climático es prácticamente inexistente.

Se asiste a un reto importante para la mejora de la enseñanza del cambio climático en las diferentes etapas escolares. Al respecto, tras la reciente aprobación (mayo de 2021) de la Ley de Cambio Climático en que se recoge un apartado específico sobre la enseñanza de este fenómeno (Título VIII "Educación, Investigación e Innovación en la lucha contra el cambio climático y la transición energética"), se especifica que el sistema educativo español reforzará el conocimiento sobre este desafío global y las capacitaciones para actividades técnicas y profesionales de la economía baja en carbono y resiliente. Se disponen de las herramientas docentes y de las normativas educativas necesarias para mejorar la formación escolar. Es necesario que estas acciones de la política educativa se vean implementadas en la realidad de las aulas y en la propia formación del profesorado de los niveles educativos no universitarios.

Como propuestas de investigación futura, será necesario llevar a cabo un análisis de la capacitación docente (profesorado actual y en formación) para trabajar esta temática en las aulas. Con ello, se podrá evitar la excesiva dependencia hacia los libros de texto y presentar, por el contrario, propuestas innovadoras que motiven al alumnado con ejemplos cotidianos y próximos a su entorno. El calentamiento climático actual es una evidencia científica avalada con datos y con efectos en los elementos atmosféricos que se manifiestan de forma diversa en cada ámbito regional. El conocimiento preciso de este proceso y su transmisión en los niveles educativos básicos es fundamental para la seguridad de la población. De ahí la importancia de la educación de esta cuestión adaptada a los diferentes niveles educativos para abordar las causas, la evolución del proceso y los efectos socio-económicos registrados y previstos por la modelización climática. Comienzan a plantearse recursos didácticos que permiten enseñar el actual calentamiento climático de forma amena, pero sin perder rigor ni caer en extremismos. Este fenómeno es un proceso silencioso y constante que está manifestando efectos de forma progresiva, de ahí la importancia de su enseñanza continuada, bien diseñada para cada etapa formativa y constantemente actualizada en el contexto educativo.

\section{REFERENCIAS BIBLIOGRÁFICAS}

Abbot, B.W. et al. (2019). Human domination of the global water cycle absent from depictions and perceptions. Nature Geoscience, 12 (7), 1-11. https://doi.org/10.1038/s41561-019-0374-y

Agencia Estatal de Meteorología (AEMET) (2020). Informe sobre el estado del clima de España 2019. Madrid. Ministerio de Transición Ecológica y Reto Demográfico, 89 p. Recuperado de http://www. aemet.es/es/conocermas/recursos_en_linea/ publicaciones_y_estudios/estudios/detalles/informe_clima_2019.

Ahmad, S. y Numan, S.M. (2015). Potentiality of disaster management education through open and distance learning system in bangladesh open university. Turkish Online Journal of Distance Education, 16 (1), 249-260. https://doi.org/10.17718/ tojde. 24161

Allea (2020). A snapshot of Climate Change Education Initiatives in Europe: Some initial findings and implications for future Climate Change Education research. Lead authors: Cliona Murphy, Gabriela Martínez Sainz, Maija Aksela, Gerd Bergman, Michael Jones, Pierre Léna, David Wilgenbus. Berlin. DOI: $10.26356 /$ climateeducation. Recuperado de https://allea.org/wp-content/uploads/2020/05/ ALLEA_Climate_Science_Education_2020-1.pdf

Allen, D.E., McAleer, M. y McHardy-Reid, D. (2018). Fake news and indifference to scientific fact: President Trump's confused tweets on global warm- 
ing, climate change and weather. Scientometrics, 117(1), 625-629. https://doi.org/10.1007/ s11192-018-2847-y

Arnell, N.W., Lowe, J.A., Challinor, A.J. y Osbom, T.J. (2019). Global and regional impacts of climate change at different levels of global temperature increase. Climatic Change, 155, 377-391. https:// doi.org/10.1007/s10584-019-02464-z.

Arrebola, J.C. y Martínez, R. (2017). El cambio climático en los libros de texto españoles de Educación Primaria: Un análisis de las actividades. En A. Cristina, E. Sande, y M. Helena. (Eds.), VIII Congreso Ibérico de Didáctica da Geografía (pp. 581-560). Lisboa, Portugal: Associação de Professores de Geografia.

Brunet, M., Jones, P., Sigro, J., Saladie, O., Aguilar, E., Moberg, A., Della-Marta, P.M., Lister, D., Walther, A. y López, D. (2007). Temporal and spatial temperature variability and change over Spain during 1850-2005. Journal of Geophysical Research, 112, D12117. https://doi. org/10.1029/2006JD008249.

Centros de Estudios y Experimentación de Obras Públicas (CEDEX) (2017). Evaluación del impacto del cambio climático en los recursos hídricos y sequías en España, Madrid, España: Ministerio de Agricultura y Pesca, Alimentación y Medio Ambiente y Ministerio de Fomento.

Chevallard, Y. (1991). La Transposition Didactique du Savoir Savant au Savoir Enseigné. Grenoble, France: La Pensée Sauvage éditions.

Chew, C. (2014). Climate change education: knowing, doing and being. Routledge.

Cramer W., Guiot J., Fader, M., Garrabou, J., Gattuso, J.P., Iglesias, A., Lange, M.A., Lionello, P., Llasat, M. C., Paz, S., Peñuelas, J., Snoussi, M., Toreti, A., Tsimplis, M.N. y Xoplaki, E. (2018). Climate change and interconnected risks to sustainable development in the Mediterranean. Nature Climate Change 8, 972980. https://doi.org/10.1038/s41558-018-0299-2

Cuello, A. (2018). Las Inundaciones del invierno 20092010 en la prensa, un recurso educativo para las ciencias sociales. Revista de Investigación en Didáctica de las Ciencias Sociales, 2, 70-87.

De Luis, M., Brunetti, M., González-Hidalgo, J.C., Longares, L. A. y Martin-Vide, J. (2010). Changes in seasonal precipitation in the Iberian Peninsula during 1946-2005. Global and Planetary Change,
74 (1), 27-33. https://doi.org/10.1016/j.gloplacha.2010.06.006

Del Río, S., Pinto, C. y Penas, A. (2011). Spatial analyses of mean temperature trends in Spain over the period 1961-2006. Global Planetary Change, 78, 65-75. https://doi.org/10.1016/j.gloplacha.2011.05.012

Del Río, S., Cano, A., Herrero, L., Penas, A. (2012). Recent trends in mean maximum and minimum air temperatures over Spain (1961-2006). Theoretical and Applied Climatology, 109, 605-626. https://doi.org/10.1007/s00704-012-0593-2

Ecoinventos (2019). Reino Unido incorpora a sus colegios a profesores especialistas en el cambio climático. Recuperado de https://ecoinventos.com/ reino-unido-incorpora-a-sus-colegios-a-profesores-especialistas-en-el-cambio-climatico/?fbclid= IwAR1bsdJD3MwOIFc0g4wYK9JRMZmVp3xPSeos 9U-57iWDI3JNWkOGAkCH1WI

Eklund, S. (2018). Climate change education with a bright horizon?: Pedagogical reflections on teacher training for climate education that aims to empower students. Tesis Doctoral.

European Environment Agency (EEA) (2017). Climate change, impacts and vulnerability in Europe 2016. An indicator-based report. Recuperado de https://www.eea.europa.eu/publications/climate-change-impacts-and-vulnerability-2016.

Fernández, R., Gómez, A. y Luengo, M. Á. (2019). Aprendiendo a interpretar el territorio: estudio de la fitotoponimia en la provincia de Salamanca. Boletín de la Asociación de Geógrafos Españoles, 82, 1-33. http://dx.doi.org/10.21138/bage.2816.

García de la Vega, A. (2016). Análisis curricular, rigor científico en los textos literarios sobre las observaciones del tiempo y clima. Propuesta didáctica con fuentes primarias. En R. Sebastiá y E. Tonda (Eds.), La investigación e innovación en la enseñanza de la Geografía (pp. 211-236). San Vicente del Raspeig, España: Servicio de Publicaciones de la Universidad de Alicante.

García, J., Pardo, P. y Rebollo, L.F. (2009). La desertificación y otros problemas ambientales en los libros de texto de geografía de educación secundaria en España. En F. Pillet, M.C. Cañizares, y A. Ruiz (Coords.), Geografía, territorio y paisaje. El estado de la cuestión: actas del XXI Congreso de Geógrafos Españoles (pp. 1757-1772). Ciudad Real, España. 
González, J.C., Peña, D., Brunetti, M. y Cortesi, N. (2015). MOTEDAS: a new monthly temperature database of Spanish continental land and the temperature trend between 1951-2010. International Journal of Climatology, 35, 4444-4463. https://doi.org/10.1002/joc.4298.

González, J. C., López, J.A., Stepanek, P., Martin-Vide, J. y De Luis, M. (2009). Monthly precipitation trends on the Mediterranean façade of the Iberian Peninsula during the second half of the 20th century (1951-2000). International Journal of Climatology, 29, 1415-1429. https://doi.org/10.1002/joc.1780

Greenwood, H. (2018). A climate change assembley. Primary Geography, 96, 22-23.

Intergovernmental Panel on Climate Change (IPCC) (2007). Fourth Assessment Report. AR4 Climate Change 2007. 3 vols. Recuperado de https:// www.ipcc.ch/assessment-report/ar4/

Intergovernmental Panel on Climate Change (IPCC) (2014). Climate Change 2013 and Climate Change 2014 (3 vols.). Recuperado de http://www.ipcc. $\mathrm{ch} /$

Intergovernmental Panel on Climate Change (IPCC) (2018). Global Warning of 1,50 C. Special Report. Recuperado de https://www.ipcc.ch/sr15/

Joint Research Centre (JRC) (2020). Diferentes informes de la Comisión Europea. Recuperado de https://ec.europa.eu/knowledge4policy/organisation/jrc-joint-research-centre_en) y https:// ec.europa.eu/jrc/en/peseta-iv.

Kažys, J. (2018). Climate change information on internet by different Baltic Sea Region languages: Risks of disinformation \& misinterpretation. Journal of Security and Sustainability Issues, 7(4), 685-695. https://doi.org/10.9770/jssi.2018.7.4(6)

Lenzen, M. y Smith, S. (1999). Teaching Responsibility for Climate Change: Three Neglected Issues. Australian Journal of Environmental Education, 15, 65-75. https://doi.org/10.1017/ S0814062600002627

Mann, M.E., Rahmstorf, S., Kornhuber, K., Steinman, B.A., Miller, S. K., Petri, S. y Coumou, D. (2018). Projected changes in persistent extreme summer weather events: The role of quasi-resonant amplification. Science Advances, 4 (10), eaat3272. https://doi.org/10.1126/sciadv.aat3272

Martín-León, F. (2019). Los inviernos serán más cálidos, pero también con irrupciones más frías.
Revista del aficionado a la meteorología, febrero. Recuperado de https://www.tiempo.com/ ram/507091/los-inviernos-seran-mas-calidos-pero-tambien-con-irrupciones-mas-frias/.

Martín-Vide, J. (2009). Diez verdades y diez mentiras en relación al cambio climático. Enseñanza de las Ciencias de la Tierra, 17 (2), 120-127.

Martínez, D.D. (2013). Situación didáctica y posibilidades del climograma como recurso digital. Didáctica Geográfica, 14, 57-68.

Martínez-Medina, R. y López-Fernández, J.A. (2016). La enseñanza de la climatología en los manuales escolares de Ciencias Sociales en Educación Primaria. En R. Sebastiá y E. Tonda (Eds.), La investigación e innovación en la enseñanza de la Geografía (pp. 245-258). San Vicente del Raspeig, España: Servicio de Publicaciones de la Universidad de Alicante.

Martínez-Fernández, L.C. y Olcina, J. (2019). La enseñanza escolar del tiempo atmosférico y del clima en España: currículo educativo y propuestas didácticas. Anales de Geografía de la Universidad Complutense, 39 (1), 125-148.

Martínez-Ibarra, E., Arias, J. y Gómez, J. (2016). La tradición oral como recurso en la enseñanza y aprendizaje del tiempo y el clima. Propuesta didáctica para el clima "Mediterráneo" de la Península Ibérica. En L. Alanís., J. Almuedo., G. De Oliveira., R. Iglesias y B. Pedregal (Eds.), Nativos digitales y geografía en el siglo XXI: Educación geográfica y estilos de aprendizaje (pp. 334-347). Sevilla, España: Universidad Pablo de Olavide, Grupo de Didáctica de la Geografía de la Asociación de Geógrafos Españoles.

Masters, M. (2020). 123 curiosidades que todo el mundo debería conocer sobre el clima, Barcelona, España: Geoplaneta.

McWhirter, N. y Shealy, T. (2018). Case-based flipped classroom approach to teach sustainable infrastructure and decision-making. International Journal of Construction Education and Research, 16, 3-23. https://doi.org/10.1080/15578771.201 8.1487892

Ministerio de Educación, Cultura y Deporte (2021). Real Decreto 1105/2014 de 26 de diciembre, por el que se establece el currículo básico de la Educación Secundaria Obligatoria y del Bachillerato. Recuperado de https://boe.es/buscar/pdf/2015/ BOE-A-2015-37-consolidado.pdf 
Monjo, R. y Martín-Vide, J. (2016). Daily precipitation concentration around the world according to several indices. International Journal of Climatology, 36 (11), 3828-3838. https://doi.org/10.1002/ joc. 4596 .

Morán, E., Herrera, S., López, J.I., Revuelto, J. y Beniston, M. (2016). Evolución reciente de las condiciones de humedad y temperatura en las montañas españolas y su relación con la cubierta nivosa. VIII Congreso Internacional Asociación Española de Climatología: Cambio climático (pp. 891-898). Alicante, España: Asociación Española de Climatología.

Morote, A.F. (2017). El Parque Inundable La Marjal de Alicante (España) como propuesta didáctica para la interpretación de los espacios de riesgo de inundación. Didáctica Geográfica, 18, 211-230.

Morote, A.F. (2020). ¿Cómo se trata el tiempo atmosférico y el clima en la Educación Primaria? Una exploración a partir de los recursos y actividades de los manuales escolares de Ciencias Sociales. Espac. Tiempo Forma Ser. VI Geogr, 13, 247-272. http://dx.doi.org/10.5944/etfvi.13.2020

Morote, A.F. y Hernández, M. (2020). Social Representations of Flooding of Future Teachers of Primary Education (Social Sciences): A Geographical Approach in the Spanish Mediterranean Region. Sustainability, 12 (15), 1-14. https://doi.org/10.3390/ su12156065.

Morote, A.F. y Moltó, E. (2017). El Museo del Clima de Beniarrés (Alicante). Propuesta de un recurso didáctico para la enseñanza de la Climatología. Didáctica de las Ciencias Experimentales y Sociales, 32 (1), 109-131. doi: 10.7203/DCES.32.9624.

Morote, A. F. y Moreno, J.R. (2021). La percepción de los futuros docentes de Educación Secundaria sobre las implicaciones territoriales del cambio climático en destinos turísticos del litoral mediterráneo. Grand Tour. Revista de Investigaciones Turísticas, 23, 261-282.

Morote, A.F. y Olcina, J. (2020). El estudio del cambio climático en la Educación Primaria: una exploración a partir de los manuales escolares de Ciencias Sociales de la Comunidad Valenciana. Cuadernos Geográficos, 59(3), 158-177. http:// dx.doi.org/10.30827/cuadgeo.v59i3.11792.

Morote, A. F. y Olcina, J. (2021). Cambio climático y sostenibilidad en la Educación Primaria. Problemática y soluciones que proponen los manuales escolares de Ciencias Sociales. Sostenibilidad: económica, social y ambiental, 3, 25-43. https:// doi.org/10.14198/Sostenibilidad2021.3.02.

Morote, A.F. y Pérez-Morales, A. (2019). La comprensión del riesgo de inundación a través del trabajo de campo: Una experiencia didáctica en San Vicente del Raspeig (Alicante). Vegueta. Anuario de la Facultad de Geografía e Historia, 19, 609-631.

Morote, A.F., Campo, B. y Colomer, J.C. (2021a). Percepción del cambio climático en alumnado de 4은 del Grado en Educación Primaria (Universidad de Valencia, España) a partir de la información de los medios de comunicación. Revista Electrónica Interuniversitaria de Formación del Profesorado, 24 (1), 131-144. https://doi.org/10.6018/reifop.393631

Morote, A. F., Hernández, M. y Olcina, J. (2021b). Are Future School Teachers Qualified to Teach Flood Risk? An Approach from the Geography Discipline in the Context of Climate Change. Sustainability, 13 (15), 8560, 1-22. https://doi.org/10.3390/ su13158560

Muñoz, C., Schultz, D. y Vaughan, G. (2020). A Midlatitude Climatology and Interannual Variability of 200- and 500-hPa Cut-Off Lows. Journal of Climate, 33(6), 2201-2222. https://doi.org/10.1175/ JCLI-D-19-0497.1

Nelles, D. y Serrer, C. (2020). El pequeño manual del cambio climático. Barcelona, España: Grijalbo.

Nieto, R. (2021). Cut-Off Lows and Extreme Precipitation in Eastern Spain: Current and Future Climate. Atmosphere, 12, 7 (835).

Núñez, J.A. (2020). Noches muy cálidas en las ciudades mediterráneas. Recuperado de https://aemetblog.es/2020/07/03/noches-muy-calidas-enlas-ciudades-mediterraneas/.

Olcina, J. (2017). La enseñanza del tiempo atmosférico y del clima en los niveles educativos no universitarios. Propuestas didácticas. En R. Sebastiá y E. M. Tonda (Eds.), Enseñanza y aprendizaje de la Geografía para el siglo XXI, (pp. 119-148). San Vicente del Raspeig, España: Servicio de Publicaciones de la Universidad de Alicante.

Olcina, J. (2020). Clima, cambio climático y riesgos climáticos en el litoral mediterráneo español. Oportunidades para la geografía. Documents d'Anàlisis Geogràfica, 66 (1), 159-182. https:// doi.org/10.5565/rev/dag.629 
Olcina, J. y Biener, S. (2019). ¿Está cambiando el clima valenciano. Realidades e incertidumbres. En Olcina, J. y Moltó, E.A. (Eds.), Climas y Tiempos en el País Valencià (pp. 162-170). Alicante, España: Publicaciones de la Universidad de Alicante.

Olcina, J., Serrano, R., Miró, J. y Meseguer, O. (2019). Tropical nights on the Spanish Mediterranean coast, 1950-2014. Climate Research, 78 (3), 225236. https://doi.org/10.3354/cr01569

Ozdem, Y., Dal, B., Ozturk, N., Sonmez, D. y Alper, U. (2014). What is that thing called climate change? An investigation into the understanding of climate change by seventh-grade students. International Research in Geographical and Environmental Education, 23, 294-313.

Parra, D. y Morote, A.F. (2020). Memoria escolar y conocimientos didáctico-disciplinares en la representación de la educación geográfica e histórica del profesorado en formación. Revista Interuniversitaria de Formación del Profesorado, 95 (34.3), 11-32. https://doi.org/10.47553/rifop. v34i3.82028.

Pastor, F. (2021). Mediterranean SST report (Winter 2021). CEAM.DOI:10.13140/RG.2.2.15096.37122.

Pastor, F., Valiente, J.J. y Khodayar, S. (2020). A Warming Mediterranean: 38 Years of Increasing Sea Surface Temperature. Remote Sens., 12, 2687. https://doi.org/10.3390/rs12172687

Peña, D., González-Hidalgo, J.C., Sandonís, L., Beguería, S., Tomas, M., López, J.A., Lemus, M. y Martín-Vide, J. (2021). Seasonal temperature trends on the Spanish mainland: A secular study (19162015). International Journal of Climatology, 41 (5), 3071-3084. https://doi.org/10.1002/joc.7006

Poortinga, W., Whitmarsh, L., Steg, L., Böhm, G. y Fisher, S., (2019). Climate change perceptions and their individual-level determinants: a crossEuropean analysis. Global Environmental Change 55, 25-35. https://doi.org/10.1016/j.gloenvcha.2019.01.007

Ríos, D., Penas, D. y Del Rio, S. (2012). Comparative analysis of mean temperature trends in continental Spain over the period 1961-2010. International Journal of Geobotanical Research 2, 41- 55. https://doi.org/10.5616/ijgr120005

Scharmacher-Schreiber, K. y Stephanie, M. (2020). ¿Cuánto calor es 1 grado más? ¿Qué pasa con el cambio climático?. Salamanca, España: Loguez Ediciones.

Serantes, A. (2015). Como abordan o Cambio Climático os libros de texto da Ensinanza Secundaria Obligatoria na España. AmbientaIMENTEsustentable, 20, 249-262. doi 10.17979/ ams.2015.2.20.1609.1603.

Serrano, R. (2017). Reconstrucción climática instrumental de la precipitación diaria en España: ensayo metodológico y aplicaciones. Tesis doctoral.

Serrano, R., Beguería, S., Saz, M.A. y De Luis, M. (2018). Recent trends reveal decreasing intensity of daily precipitation in Spain. International Journal of Climatology, 38, 4211-4224. https://doi. org/10.1002/joc.5562

Shepardson, D.P. y Hirsch, A.S. (2020). Teaching climate change. What educators should know and can do. American Educator, 20, 4-13.

Tonda, E., y Sebastiá. R. (2003). Las dificultades en el aprendizaje de los conceptos de tiempo atmosférico y clima: la elaboración e interpretación de climogramas. Revista de Educación de la Universidad de Granada, 16, 47-69.

Valbuena, M. y Valverde, J.A. (2006). La climatología local. Procedimiento para su enseñanza y aprendizaje. Didáctica Geográfica, 8, 93-108.

United Nations (2015). Sustainable Development Goals. UNDP, Sustainable Development Agenda. Recuperado de https://www.undp.org/content/ undp/es/home/sustainable-development-goals/ resources.html.

Ward, P.J. et al. (2020). Review article: Natural hazard risk assessments at the global scale. Nat. Hazards Earth Syst. Sci., 20, 1069-1096. https://doi. org/10.5194/nhess-20-1069-2020.

Wetterzentrale (2020). Mapas de tiempo. Recuperado de https://www.wetterzentrale.de/

White, G. F. (1974). Natural hazards, local, national, global. United Kingdom: Oxford University Press.

Wisner, B., Blaikie, P., Cannon, T. y Davis, I. (2004). At risk. Natural hazards, people's vulnerability, and disasters. London and New York: Routledge.

Woollings, T. (2019). A battle for the jet stream is raging above our heads. The Conversation, november, 14. https://theconversation.com/a-battle-for-the-jet-stream-is-raging-above-our-heads-125906. 